Ensino, Saúde e Ambiente - v. 14 n. esp. (2021): Dossiê Paulo Freire para além dos 100 anos:

construir utopias, transformar a realidade, p. 230-244.

Lutas Sociais e Educação Popular

ENSINO, SAÚDE E AMBIENTE

\title{
Movimentos sociais, alternativas ao desenvolvimento e construção educativa popular na América Latina
}

\author{
Social movements, alternatives to development and popular \\ educational construction in Latin America
}

\section{Larissa Thomaz Coelho ${ }^{1}$; Leilane Reis ${ }^{2}$ e Liara Bambirra ${ }^{3}$}

1 Advogada. Mestre em Direito, Políticas Públicas e Sustentabilidade (UNIRIO) Pesquisadora do GRISUL. Rio de Janeiro, RJ, Brasil. E-mail: larissathomazc@gmail.com

2 Doutoranda em Direito (PUC/RJ). Pesquisadora da RESAMA e do GRISUL. Consultora na RaceandEquality. Rio de Janeiro, RJ, Brasil. E-mail: leilanereis@gmail.com / ORCID https://orcid.org/0000-0001-7208-5830

3 Educadora Popular e Cientista Política. Mestranda em Ciências Sociais, Desenvolvimento, Agricultura e Sociedade (CPDA/UFRRJ). Pesquisadora do GRISUL. Rio de Janeiro, RJ, Brasil. E-mail: liarabambirra@hotmail.com

\section{Palavras-chave: desenvolvimento; extrativismo; educação popular; extrativismo; resistência.}

RESUMO: O presente trabalho tem como objetivo entender as lutas sociais na América Latina e Caribe que resistem ao modelo de desenvolvimento hegemônico, em uma percepção de suas trajetórias como agentes fundamentais na construção pedagógica popular. São os movimentos sociais e comunidades de atingidos que formulam as alternativas a esse modelo, que dita de forma desigual e dependente a formação política e social desses países. $O$ artigo nasce com a proposta de relacionar os processos e práticas insurgentes para resistir, (re)existir e (re)viver pedagogias, ligados ao que Paulo Freire (2003) chamou de "motivos de esperança no desespero". A partir do trabalho construído coletivamente na Cartilha Pacha: defendendo a terra, publicada em 2018 pelo Grupo de Relações Internacionais e Sul Global da Universidade Federal do Estado do Rio de Janeiro (GRISUL-UNIRIO) ${ }^{[1]}$, o artigo articula particularmente os aprendizados tecidos na resistência de mulheres atingidas pelo Extrativismo com a educação popular.

[1] Disponível em: http://www.grisulunirio.com/pacha/

\section{Keywords:}

development; extractivism; popular education; extractivism; resistance.
ABSTRACT:The present work aims to understand the social struggles in Latin America and the Caribbean that resist the hegemonic development model, in a perception of their trajectories as fundamental agents in the popular pedagogical construction. It is the social movements and communities of those affected that formulate alternatives to this model, which dictates the political and social formation of these countries in an unequal and dependent manner. The article was born with the proposal to relate the insurgent processes and practices to resist, (re)exist and (re)live pedagogies, linked to what Paulo Freire (2003) called "reasons for hope in despair". Based on the work collectively constructed in the Pacha Booklet: defending the land, published in 2018 by the International Relations Group and the Global South of the Federal University of the State of Rio de Janeiro (GRISUL-UNIRIO), the article particularly articulates the learning woven into the resistance of women affected by Extractivism with popular education. 
Ensino, Saúde e Ambiente - v. 14 n. esp. (2021): Dossiê Paulo Freire para além dos 100 anos:

construir utopias, transformar a realidade, p. 230-244.

Lutas Sociais e Educação Popular

\section{INTRODUÇÃ̃}

O modelo de desenvolvimento que rege as relações econômicas e sociais existentes em todo o mundo impacta de maneiras diferentes as mais variadas regiões do planeta. Isso quer dizer que a situação de desigualdade na qual se encontram, de um lado, os países ricos e, de outro, aqueles em desenvolvimento, não somente se mantém, mas se agrava e se aprofunda à medida que referido modelo permanece sem ser revisto ou questionado, passando a revelar a posição de dependência ocupada pelos países exportadores de matéria-prima em relação àqueles exploradores.

Mesmo com a consolidação dos Estados nacionais, este modelo de produção se fortaleceu e, apesar das transformações, atualmente a região permanece como uma das principais exportadoras de matérias primas do mundo (GRISUL, 2018). Por isso, é muito importante compreender o papel central do extrativismo, entendido como uma forma de acumulação e exploração dos recursos naturais que não considera os limites dos recursos naturais, nem a prática das práticas utilizadas.

É nesse contexto que surgem os movimentos socioambientais, que, ao mesmo tempo lutam pela sua sobrevivência, tecem alternativas ao modelo de desenvolvimento capitalista. Em verdade, essas duas ações não são realizadas em separado ou de maneira dissociada. Ao contrário, o que se percebe é que, ao resistir, constroem alternativas; ao lutar, constroem conhecimento. Nesse sentido, o presente estudo busca demonstrar que referidos movimentos, apesar de constantemente criminalizados, estão abrindo importantes caminhos e alternativas ao desenvolvimento.

Nesse sentido, e apresentando como base os movimentos de resistência como produtores de saberes tradicionais, destaca-se a importância da educação ambiental para a divulgação desse conhecimento. Por meio de uma articulação do pensamento de Paulo Freire com os movimentos socioambientais, especificamente aqueles inseridos no contexto da América Latina - conforme o conteúdo apresentado na Cartilha Pacha - Defendendo a Terra $^{[1]}$-, este estudo se destinará a investigar o papel dos espaços de resistência como agentes construtores de processos populares de educação, que podem nos indicar caminhos emancipatórios para os territórios estudados na Cartilha. 
Ensino, Saúde e Ambiente - v. 14 n. esp. (2021): Dossiê Paulo Freire para além dos 100 anos:

construir utopias, transformar a realidade, p. 230-244.

Lutas Sociais e Educação Popular

\section{EXTRATIVISMO E MOVIMENTOS SOCIAIS NA AMÉRICA LATINA E CARIBE}

$\mathrm{O}$ atual modelo capitalista que rege as relações econômicas e sociais existentes em todo o mundo impacta de maneiras diferentes as mais diversas regiões do planeta. Dentre as mais afetadas por esse modo de produção, encontra-se a área correspondente à América Latina e Caribe, que, desde o momento em que foi tomada pelos chamados colonizadores europeus, sofreu com a exploração de seus recursos naturais e de suas populações, bem como perdeu poder e soberania sobre seu próprio território, configurando-se, assim, como um conjunto de colônias dos mais diversos países do "além-mar".

É nesse contexto que é possível perceber que os países que atualmente fazem parte da América do Sul e Caribe encontram-se inseridos no modelo econômico mundial de forma desigual desde o período de sua colonização. Mesmo após tornarem-se nações independentes do ponto de vista político, o fato é que, quando realizada uma análise sob a ótica da economia, constata-se que esses países ainda travam uma relação de dependência com os Estados ditos "desenvolvidos", ocupando, assim como na era colonial, a posição de fornecedor das matérias-primas necessárias para o desenvolvimento dos países ricos.

Dessa maneira, a economia primária exportadora faz parte da formação social e política dos países latino-americanos e caribenhos e continua a costurar o modelo de dependência imposto a esses territórios. O extrativismo, então, é uma prática que explica a acumulação, concentração, devastação colonial e neocolonial, bem como a evolução do capitalismo moderno e até mesmo as ideias de desenvolvimento e subdesenvolvimento, como dois lados do mesmo processo (ACOSTA, 2017).

Maristella Svampa (2012) ressalta como o desenvolvimento extrativista faz permanecer as relações de colonialidade na América Latina, e defende o extrativismo como categoria potente para entender o desenvolvimento e os discursos que ele carrega. Há uma persistente colonialidade que afeta a natureza latino-americana, mas também o imaginário social sobre o que é progresso, o que é desenvolvimento. Svampa (2012; 2019), nesse sentido, reivindica o extrativismo como uma janela de análise "privilegiada" para ler as múltiplas crises que os territórios latino-americanos atravessam nos últimos anos 
Ensino, Saúde e Ambiente - v. 14 n. esp. (2021): Dossiê Paulo Freire para além dos 100 anos: construir utopias, transformar a realidade, p. 230-244.

\section{Lutas Sociais e Educação Popular}

As economias latino-americanas aprofundaram sua inserção global subordinada e sua dependência em relação aos países e mercados globais (GRISUL, 2018). Essa expansão do extrativismo está tendo consequências irreversíveis sobre os territórios e seus habitantes.

É notório, portanto, que não somente operou-se a manutenção do modelo produtivo primário-exportador das nações latino-americanas e caribenhas, como também houve um aprofundamento do referido modelo, de modo a fazer com as nações da região aqui estudada estejam situadas na periferia internacional no aspecto o econômico, social e até mesmo o político - restando inegável, pois, principalmente quanto a este último, a conclusão de que a descolonização não conferiu aos novos Estados Nacionais independência efetiva e plena.

Assim, a realidade é que a América Latina e Caribe continua tendo suas riquezas e recursos naturais explorados pelos países ricos de forma desmedida, sendo a atividade extrativista a maneira mais relevante pela qual essa usurpação é realizada. Sem se importar com meio ambiente, com a sustentabilidade, com os povos, nem com a limitação e finitude dos recursos, o extrativismo realizado nesses países utiliza, em sua maioria, práticas cruéis, ilegais e abusivas, visando somente ao lucro e crescimento das nações que se autoproclamam desenvolvidas, impondo práticas extremamente danosas, apoiadas, apoiados, ainda, por aparatos políticos e econômicos dos Estados.

Toda conjuntura acima descrita revelou-se como verdadeiro berço para o surgimento de grupos que questionam a exploração, a ela resistem e contra ela lutam: os movimentos sociais. E são todas essas situações existentes que fazem com que a América Latina e Caribe seja, nos dias de hoje, a região mais perigosa do mundo para os defensores da terra e os ambientalistas viverem e exercerem suas missões.

Segundo dados mais recentes do Global Witness, no ano de 2019 registrou-se o maior número de assassinatos de ativistas ambientais no período de um ano (212 homicídios), sendo mais de dois terços desses crimes aconteceram em países latino-americanos e caribenhos, reforçando a classificação conferida à região em estudo como a mais violenta desde que a mencionada organização iniciou a publicação de dados de suas pesquisas em 2012 (GLOBAL WITNESS, 2021).

Deve-se lembrar que essa é apenas uma das formas de abuso e coação utilizadas pelos detentores do dinheiro e poder para silenciar aqueles que lutam para defender sua terra, seu espaço e seus direitos: violência moral, física, sexual, ameaças e criminalização da resistência 
Ensino, Saúde e Ambiente - v. 14 n. esp. (2021): Dossiê Paulo Freire para além dos 100 anos: construir utopias, transformar a realidade, p. 230-244.

\section{Lutas Sociais e Educação Popular}

acontecem a todo o momento com o intuito de calar qualquer ativismo que representa um impasse à exploração desmedida da terra.

Contudo, é preciso destacar que, mesmo diante desse cenário conflituoso e turbulento, no qual o simples ato de existir e querer viver a própria cultura em seu próprio território é considerado uma afronta aos ditames capitalistas, os movimentos sociais trazem no bojo da sua luta o desejo de construir alternativas ao modelo extrativista atualmente praticado, de levantar soluções para os problemas decorrentes dessa atividade. Porém, não é a essa faceta de referidos movimentos que se dá ampla visibilidade; ao contrário, mais interessa aos extrativistas torná-la desconhecida, ou pior: repudiá-la e criminalizá-la.

\subsection{PACHA: DEFENDENDO A TERRA. EXTRATIVISMO, CONFLITOS E RESISTÊNCIAS NA AMÉRICA LATINA E CARIBE}

A grave situação atualmente vivenciada pelos grupos e povos na América Latina e Caribe vem, pouco a pouco, tornando-se mais conhecida. Cientes de que as informações sobre o que ocorre em referida região não são somente insuficientes e esparsas, como também rasas e, muitas vezes, imprecisas e distorcidas, é que surgiu, dentro do Grupo de Pesquisa em Relações Internacionais e Sul Global (GRISUL), da Universidade Federal do Rio de Janeiro (UNIRIO), o interesse em estudar a questão e aprofundar os entendimentos sobre a conturbada relação entre a exploração extrativista e a atuação dos movimentos sociais.

Cerca de dois anos após o início das pesquisas, o referido Grupo de estudos lançou, em 2018, a Cartilha "Pacha: Defendendo a Terra. Extrativismo, conflitos e alternativas na América Latina e Caribe”. Disponível de forma gratuita e online no sítio eletrônico do GRISUL, essa Cartilha traz em seu conteúdo a análise de dez conflitos marcantes e ilustrativos dentre os mais de duzentos e cinquenta e nove existentes na região envolvendo a atividade extrativista mapeados à época. A escolha dos casos foi realizada tendo como base eixos paradigmáticos, tais como o ambiental, feminista e afrodescendente. Nos dizeres da própria Pacha:

(...) visibilizaremos os impactos do extrativismo sobre o meio ambiente, as lutas e resistências das mulheres, indígenas e afrodescendentes, assim como as ações de empresas transnacionais como a Vale. Mostraremos também alguns exemplos de 
Ensino, Saúde e Ambiente - v. 14 n. esp. (2021): Dossiê Paulo Freire para além dos 100 anos: construir utopias, transformar a realidade, p. 230-244.

Lutas Sociais e Educação Popular

deslocamentos forçados e criminalização dos movimentos e analisaremos alternativas formuladas a partir das cosmovisões dos povos de América Latina e Caribe (GRISUL, 2018, s/p).

A Cartilha analisa os conflitos nela apresentados utilizando como base os ensinamentos e postulados da teoria denominada de Ecologismo dos Pobres ou Movimento de Justiça Ambiental, como defende Joan Martinez Alier[2]. O estudo dos conflitos ambientais ilumina o conteúdo ecológico presente em muitos conflitos sociais (Alier, 2006). Os conflitos ambientais mostram que há, nesses conflitos, distintos atores que possuem distintos interesses, valores, culturas, saberes e também desiguais níveis de poder, que utilizam através de linguagens de valoração (Alier, 2008).

Nesse contexto, a Pacha tem como objetivo dar visibilidade àqueles que atuam defendendo seus territórios e seus recursos da exploração pelo extrativismo. E vai além: visa demonstrar que, diferentemente do que o atual modo de exploração capitalista rotula, a luta e resistência dos movimentos sociais não são reações violentas e/ou criminosas à atividade econômica realizada em suas regiões, mas verdadeiros questionamentos e contestações à atual maneira como é conduzido o modelo desenvolvimentista de matriz extrativista contemporâneo.

Assim, a Cartilha, ao invés de simplesmente apresentar os atores sociais do ativismo pela terra como simples "objetos" ou "vítimas", destaca-os como promotores de alternativas que são, em verdade, ao modelo de desenvolvimento hegemônico. A luta e resistência dos povos e ambientalistas não se configuram como fins em si mesmos, mas como reais propostas de soluções, de formulação de ideias e de genuínos ensinamentos, aos quais devem ser dada a devida visibilidade e propagação para que possam ir além de seus próprios contextos. E é exatamente diante dessa constatação que torna-se possível entender como os conhecimentos e informações elaborados pelos movimentos sociais possuem um fundamental papel na construção de processos populares de educação. 
Ensino, Saúde e Ambiente - v. 14 n. esp. (2021): Dossiê Paulo Freire para além dos 100 anos:

construir utopias, transformar a realidade, p. 230-244.

Lutas Sociais e Educação Popular

\section{CONSTRUÇÃO De ALTERnAtivas: A RESistênCIA PROTAGONizAdA POR MULHERES}

A mineração realizada de forma predatória contamina o meio ambiente e colabora para a crise climática que vivenciamos, afetando diretamente a saúde das comunidades ao redor. Percebe-se a manutenção da ideia onde o homem - especialmente se branco, heteressexual, estadunidense ou europeu, e dono de propriedades - permanece como centro, colocando a natureza como mero objeto de exploração e sustentação do seu bem estar, tantas vezes atrelado a consumos e tecnologia sem o menor cuidado ambiental. Esse modelo de desenvolvimento deve ser desconstruído - afinal, sustenta uma lógica colonial e patriarcal. A busca de construção de alternativas que questionem o atual modelo predatório faz-se essencial na construção de um bem-estar coletivo.

É preciso, portanto, buscar uma "consciência socioambiental revolucionária" (MARES, P. 39), para conseguirmos mitigar os efeitos devastadores da já vivida degradação ambiental, retornando o olhar para os saberes tradicionais, voltando a colocar o ser humano e o meio ambiente no mesmo local de cuidado.

Para pensarmos, portanto, na construção de alternativas, é preciso buscar a ideia de novos mundos, onde a prática atual predatória e com o homem como centro do mundo não seja mais dominante. A ideia vigente de separar o homem da natureza, e da visão antropocêntrica como única, não se sustenta ao pensarmos em um novo viver comunitário. Propostas de alternativas de rompimento já existem e são colocadas em práticas através de lutas e iniciativas de movimentos sociais, e de teorias como o ecofeminismo, o Bem Viver, o comum.

No recorte aqui pretendido, destacamos os movimentos socioambientais, que contestam a divisão espacial promovido pelo capital através da luta de resistência de mulheres. As lutas em prol da justiça ambiental estão relacionadas à vida da coletividade, já que os objetivos desses movimentos estão correlacionados com os bens fundamentais para a vida: a energia, a água, o seu local de moradia, a terra.

Villareal e Echart (2019) ressaltam que o extrativismo afeta principalmente a vida, os corpos e os territórios das mulheres, tanto na promoção de projetos de mineração quanto na expansão da monocultura ou outras atividades de exploração intensiva dos recursos naturais. 
Ensino, Saúde e Ambiente - v. 14 n. esp. (2021): Dossiê Paulo Freire para além dos 100 anos: construir utopias, transformar a realidade, p. 230-244.

\section{Lutas Sociais e Educação Popular}

Há, portanto, um reconhecimento crescente de que esses efeitos são desiguais, sentidos e resistidos de forma diferenciada. A sobrecarga de trabalho e a violência gerada por esses conflitos adquire características específicas para as mulheres, por exemplo, em que a violência sexual e o uso de as violações coletivas passam a costurar uma forma de punição ou retaliação às ações promovidas pelos movimentos de resistência aos projetos de desenvolvimento (INSTITUTO PACS, 2021).

A partir de elementos como militarização, ocupação de territórios, contaminação de recursos naturais, desintegração do tecido social e desarticulação das economias locais, as mulheres são especialmente afetadas como mães e provedoras domésticas (CIDH 2015). Maristella Svampa (2019) chama a atenção para a masculinização dos territórios com atividade de mineração.

A autora ressalta que são espaços que reforçam o patriarcado, favorecendo uma rede de exploração sexual de corpos femininos e tráfico de mulheres. Para a autora, em toda a região latino-americana há uma relação entre a mineração, a prostituição e o tráfico de mulheres. Há, ainda, um grande aumento da violência estatal e paraestatal direcionada às mulheres, que também são forçadas a se deslocar. Assim, nesses espaços masculinizados, as problemáticas sociais são intensificadas, como a desigualdade de gênero.

Certamente, não se pode colocar como desenvolvimento um projeto sustentado em cima de corpos que permanecerão na esfera da pobreza e da dominação. Segundo Vandana Shiva $(2004, \mathrm{~s} / \mathrm{p})$ :

A velha suposição de que o processo de desenvolvimento aumentaria automaticamente a disponibilidade de bens e serviços e a pobreza seriam eliminados está seriamente contestado por movimentos ambientais do Terceiro Mundo, embora continue a guiar ideias sobre o desenvolvimento nos centros do poder patriarcal. (...) A sobrevivência é baseada no pressuposto da santidade da vida; mau desenvolvimento, no caráter sagrado de "desenvolvimento".

Mendonza (2014) chama atenção para a necessidade de destaque de uma teoria feminista latino-americana que rompa os cinco séculos de colonização ao conhecimento eurocentrado e masculino. De fato, em razão da violência sofrida pelos corpos femininos no contexto do neoextrativismo, e também porque a atividade está concentrada na região, faz-se necessária a visibilidade da luta das mulheres tanto no campo teórico, como na prática das 
Ensino, Saúde e Ambiente - v. 14 n. esp. (2021): Dossiê Paulo Freire para além dos 100 anos: construir utopias, transformar a realidade, p. 230-244.

\title{
Lutas Sociais e Educação Popular
}

lutas sociais. É importante frisar que a ação desses movimentos é capaz de contemplar coletivamente os territórios e suas populações. Novamente, destaca-se o ensinamento de Vandana Shiva (2004, s/p):

\begin{abstract}
A recuperação do princípio feminino permite-nos transcender os fundamentos patriarcais do mau desenvolvimento e transformá-los. Ele permite que você redefina o crescimento e a produtividade como categorias ligadas à produção - não à destruição - da vida. Então isso é um projeto político, ecológico e feminista ao mesmo tempo, que legitima a vida e a diversidade, e que retira a legitimidade do conhecimento e da prática de uma cultura da morte que serve como base para a acumulação de capital.
\end{abstract}

As mulheres possuem organizações onde conseguiram frear o projeto de desenvolvimento, assim como postular perante as Cortes Internacionais de direitos humanos a violação dos seus direitos. Resistem contra a ausência de representatividade nos processos de elaboração de políticas públicas, e de nos processos de decisão (GRISUL, 2018). Construir alternativas com os saberes e diálogos com mulheres, especialmente amefricanas e ameríndias (GONZALES, 1988) é fundamental para frear o retrocesso dos direitos humanos, bem como os impactos da desigualdade fomentada pela política de dependência que permanece vigente na região.

Na Cartilha Pacha, entre os movimentos de resistência analisados, foi destacado o caso de Piquiá de Baixo. A região, altamente afetada pelo complexo siderúrgico ao seu redor, é exposta a altos índices de poluição no ar e na água, que atingem diretamente a comunidade local. As mulheres se mobilizaram para fazer o monitoramento da poluição, bem como buscar estratégias de reassentamento para a comunidade, impedida de manter seu modo de vida em razão das alterações socioambientais, conflitando diretamente com as empresas siderúrgicas, e a Vale, também presente na região. Com tais ações, as mulheres denunciam a violação de direitos humanos, nos seus corpos e territórios.

Os saberes dessas mulheres, colocados em forma de educação e de luta, torna-se fundamental para pensarmos na construção de alternativas em prol de uma coletividade que valorize a vida, reduzindo práticas patriarcais, racistas e colonizadoras. A educação popular parte da escuta dessas vozes contra hegemônicas, que desafiam as premissas colocadas pelo modelo liberal extrativista. Assim, a produção de conhecimento fomentada pelos movimentos sociais de mulheres deve ocupar posição de protagonismo na defesa da terra. 
Ensino, Saúde e Ambiente - v. 14 n. esp. (2021): Dossiê Paulo Freire para além dos 100 anos: construir utopias, transformar a realidade, p. 230-244.

Lutas Sociais e Educação Popular

\section{MOVIMENTOS SOCIAIS E EDUCAÇÃO POPULAR}

Nilma Lino Gomes (2017) ressalta que os movimentos sociais são produtores e articuladores de saberes construídos por grupos não hegemônicos e contra-hegemônicos da nossa sociedade. Segundo a autora, esses movimentos:

\footnotetext{
Atuam como pedagogos nas relações políticas e sociais. Muito do conhecimento emancipatório produzido pela sociologia, antropologia e educação no Brasil se deve ao papel educativo desempenhado por esses movimentos, que indagam o conhecimento científico, fazem emergir novas temáticas, questionam conceitos e dinamizam o conhecimento. (GOMES, 2017, p. 17)
}

As práticas e políticas educacionais, reguladas pelo mercado e pela racionalidade científico-instrumental, têm dificuldade em reconhecer esses saberes produzidos pelos movimentos sociais e pelos setores populares. Assim, esses saberes foram transformados em não existência, ou seja, em ausências.

A educação popular reivindica a importância dos saberes construídos e reconstruídos pelos setores populares, pelas mulheres, pelos movimentos ambientalistas. Reconhecê-los, portanto, é fundamental para construirmos saberes emancipatórios capazes de questionar essa pedagogia conservadora. A pedagogia da diversidade (FREIRE, 1999) caminha exatamente nesse sentido, ao tensionar o processo pedagógico tradicional que ainda ocupa um lugar hegemônico no campo científico, configurando-se em uma pedagogia da regulação. $\mathrm{Na}$ pedagogia da diversidade, a educação é vista como prática da liberdade, como um ato de amor, um ato político e, por isso, um ato de coragem (FREIRE, 1999).

Um grupo de pesquisadoras ${ }^{[3]}$, ao refletir sobre a Pedagogia Feminista como processo educativo para a reflexão da política pública de ATER (Assistência Técnica e Extensão Rural) no Nordeste, mostram que a ciência ou conhecimento formal foram durante muito tempo negado às mulheres e os seus saberes/fazeres e a construção do conhecimento gerado por elas foi e ainda é historicamente invisibilizado e/ou desvalorizado sendo reconhecido como crendices ou ainda práticas culturais tradicionais. E acrescentam: 
Ensino, Saúde e Ambiente - v. 14 n. esp. (2021): Dossiê Paulo Freire para além dos 100 anos: construir utopias, transformar a realidade, p. 230-244.

\section{Lutas Sociais e Educação Popular}

Desta forma, se enquadram todo o conhecimento do manejo de plantas medicinais, das ervas sagradas e de poder, das parteiras, raizeiras, curandeiras, do cuidado, da criação de pequenos animais, das outras formas de produção e economia, etc. Urge reconhecermos esses saberes como imprescindíveis à reprodução da vida e toda a contribuição das mulheres às práticas agroecológicas, como forma de complexificar os processos de transição agroecológica e reafirmar nosso entendimento da agroecologia enquanto ciência, movimento e prática (2018, p. 14).

É fundamental ressaltar as mulheres como portadoras de saberes indispensáveis para a reprodução da agroecologia, do campesinato, pilares imprescindíveis de uma educação popular comprometida com o Bem Viver, palavra quéchua que significa natureza, terra, mundo e universo e que tem inspirado as lutas em defesa da nossa mãe terra, a Pacha Mama, e que nos guiou para nomear a Cartilha que costura este trabalho.

Catherine Walsh propôs o conceito de "pedagogias descoloniais" para dar conta de uma modalidade peculiar de processo de ensino-aprendizagem fora das formas canônicas de compreender o conhecimento na tradição ocidental. As pedagogias decoloniais são entendidas como espaços genuinamente educacionais, colocando em tensão a dimensão colonial e a opressão dentro de processos pedagógicos, concebidos a partir de uma verticalidade hierárquica. Walsh expressa:

As lutas sociais também são cenários pedagógicos onde os participantes exercem suas pedagogias de aprendizagem, desaprendizagem, reaprendizagem, reflexão e ação. É apenas para reconhecer que as ações destinadas a mudar a ordem do poder colonial muitas vezes partem da identificação e reconhecimento de um problema, anunciar desacordo com e oposição à condição de dominação e opressão, organizando-se para intervir; o objetivo: derrubar a situação atual e tornar possível outra coisa. Tal processo de ação, normalmente realizado coletivamente e não individual, suscitar reflexões e ensinamentos sobre a situação / condição colonial em si e o projeto inacabado de descolonização, ao mesmo tempo que chamam a atenção para as práticas políticas, epistêmicas, experienciais e existenciais que lutam para transformar os padrões de poder e os princípios sobre os quais o conhecimento, a humanidade e a própria existência foi circunscrita, controlada e subjugada. As pedagogias, neste sentido, são as práticas, estratégias e metodologias que estão entrelaçados e construídos com base na resistência e na oposição, como na insurgência, fuga, afirmação, reexistência e re-humanização (WALSH, 2013, p. 29). 
Ensino, Saúde e Ambiente - v. 14 n. esp. (2021): Dossiê Paulo Freire para além dos 100 anos:

construir utopias, transformar a realidade, p. 230-244.

\section{Lutas Sociais e Educação Popular}

As práticas e metodologias entrelaçadas às lutas resistência, visibilizadas dentro da Cartilha Pacha, são indispensáveis para cultivar e colher vida diante dos projetos de morte física, cultural, espiritual e territorial.

\section{CONCLUSÃO}

Apostar na possibilidade de recuperar as experiências como produtoras de conhecimento e capazes de criar teoria é um importante caminho para um horizonte político emancipatório, a partir do exercício contínuo que desarticule a distinção entre conhecimento puro e conhecimento político, pois uma prática libertadora entende que não há separação entre os dois.

Visibilizar e dar espaço aos saberes e movimentos dentro e fora do ambiente acadêmico é também fundamental. $O$ estudo crítico desses saberes produzidos na tensão regulação-emancipação social traz para a teoria pedagógica novos conhecimentos, além de compreender novos processos de produção do conhecimento e nos pressiona a repensar conceitos, termos e categorias analíticas por meio dos quais os processos educativos dentro e fora da Academia têm sido interpretados via a racionalidade científico-instrumental.

É de suma importância, também, reconhecer e formular instrumentos metodológicos que dêem conta desta proposta e dialogue com as distintas realidades enfrentadas pelos movimentos sociais em toda América Latina e Caribe, como nos ensina Nilma Lino Gomes (2017):

É importante compreender que as fronteiras entre os diversos movimentos sociais e ações emancipatórias não precisam ser necessariamente barreiras ou zonas de conflito. Elas podem ser pontos de contato, livre-trânsito entre os diferentes movimentos sociais, com capacidade interna e externa de mobilização, vigilância epistemológica e resistência democrática.” (GOMES, 2017,p. 140)

Ao longo deste estudo, constatou-se a importância dos movimentos socioambientais como protagonistas na construção de alternativas ao modelo desenvolvimentista atual, em especial o aquele liderado por mulheres. Desmistificar a ideia de que a luta e a resistência dos povos e ambientalistas são atos criminosos é urgente. É preciso demonstrar a todo momento, 
Ensino, Saúde e Ambiente - v. 14 n. esp. (2021): Dossiê Paulo Freire para além dos 100 anos: construir utopias, transformar a realidade, p. 230-244.

Lutas Sociais e Educação Popular

o real e verdadeiro sentido de referidos movimentos: o de produzir conhecimento para que se possa, finalmente, sedimentar a paz. Resgatando os aprendizados de Paulo Freire, em que "o mundo não é, está sendo", que os movimentos sociais sejam guia para a transformação desta forma como habitamos nossas terras.

\footnotetext{
${ }^{[1]}$ Disponível em: http://www.grisulunirio.com/pacha/

[2]O ecologismo dos pobres, ou ecologismo popular, ou movimento de justiça ambiental (ALIER, 2007, p. 33), surge como terceira corrente do ecologismo. A primeira é chamada por Martinez Alier de "culto ao silvestre"; já a segunda, de "credo da ecoeficiência". Essa construção teórica parte da luta e da resistência dos pobres pelo seu território e para a manutenção dos recursos naturais que são fundamentais para a sua sobrevivência.

${ }^{[3]}$ MORAES, Lorena Lima de; JALIL, Laeticia Medeiros; SANTOS, Janaína Henrique dos; COSTA, Michelly Aragão Guimarães; OLIVEIRA, Maria do Socorro de Lima
}

\section{REFERÊNCIAS}

ACOSTA, A. Poscrecimiento y posextractivismo. Dos caras de lamismatransformación cultural.En: Rebelión, 27 de marzo de 2015.

ALIER, J M. Conflictos ecológicos y justicia ambiental. Revista nº 103. Em: 1732369365 , Disponível em: fuhem.com. 2008.

ALIER, J M. Los conflictos ecológico-distributivos y los indicadores de sustentalibidad. 2006.

ECHART, E; VILLARREAL, M C. Resistencias y alternativas al desarrolloen América

Latina y Caribe: luchas sociales contra elextractivismo. Relaciones Internacionales, 2018.

FREIRE, P. El grito manso. Buenos Aires: Siglo XXI. 2003.

FREIRE, P. Pedagogia da autonomia - Saberes necessários à prática pedagógica. 15. ed.

São Paulo: Paz e Terra, 2000.

FREIRE, P. Pedagogia da esperança - Um reencontro com a pedagogia do oprimido. 6 . ed. São Paulo: Paz e Terra, 1999.

GLOBAL WITNESS. Global Witness registra o maior número de assassinatos de ativistas da terra e do meio ambiente em um ano, vinculados ao preocupante avanço das mudanças climáticas. https://www.globalwitness.org/pt/global-witness-records-the-highest- 
Ensino, Saúde e Ambiente - v. 14 n. esp. (2021): Dossiê Paulo Freire para além dos 100 anos: construir utopias, transformar a realidade, p. 230-244.

Lutas Sociais e Educação Popular

number-of-land-and-environmental-activists-murdered-in-one-year-with-the-link-toaccelerating-climate-change-of-increasing-concern-pt/. Acesso em: 23 de junho de 2021.

GRISUL. P. Defendendo a terra. Extrativismo, conflitos e alternativas na América Latina e Caribe. UNIRIO: Rio de Janeiro, 2018. Disponível em: http://www.grisulunirio.com/. Acesso em: 29 jul. 2019.

GOMES, N L. O movimento negro educador: saberes construídos nas lutas por emancipação. 2017.

INSTITUTO POLÍTICAS ALTERNATIVAS PARA O CONE SUL (PACS). Mulheres Atingidas: Territórios Atravessados por Megaprojetos. 2021.

MARÉS, C. De como a natureza foi expulsa da modernidade. Revista de Direitos Difusos, v. 68, n. 1, p. 15-40, 2017.

MENDOZA, B. 2010. La epistemologia del sur, la colonialidad del género y el feminismo latinoamericano. In: MIÑOSO, Y E (coord). Aproximaciones críticas a las prácticas teórico-políticas del feminismo latinoamericano - Vol.1: 19-36, Buenos Aires: Enla Frontera

MORAES, L L de; JALIL, L M; SANTOS, J. H. dos; COSTA, M A G; OLIVEIRA, M do S de L. Pedagogia Feminista como processo educativo para a reflexão da política pública de ATER no Nordeste. 2018.

QUEIROZ, A. L., \& PRAÇA, M. (2020). Dos impactos à defesa: mulheres, corposterritórios e direitos humanos. Disponível em Biblioteca Berta Cáceres - Instituto Pacs: http://biblioteca.pacs.org.br/publicacao/dos-impactos-a-defesa-mulheres-corpos-territorios-edireitos-humanos/

SHIVA,V. La mirada delecofeminismo (tres textos), Polis [En línea], 9 | 2004, Publicadoel 22 octubre 2012, consultado el 01 julio 2021. URL:

http://journals.openedition.org/polis/7270. Acesso em 28 de junho de 2021

SVAMPA, M. As fronteiras do neoextrativismo na América Latina. Conflitos socioambientais, giro ecoterritoriale novas dependências. Trad. Ligia Azevedo. São Paulo, Ed. Elefante, 2019

SOBRE AS AUTORAS

\section{LARISSA THOMAZ COELHO}

Advogada. Mestre em Direito, Políticas Públicas e Sustentabilidade pelo Programa de PósGraduação em Direito da Universidade Federal do Estado do Rio de Janeiro. Pesquisadora do Grupo de Pesquisa em Relações Internacionais e Sul Global (GRISUL). Avaliadora de artigos 
Ensino, Saúde e Ambiente - v. 14 n. esp. (2021): Dossiê Paulo Freire para além dos 100 anos: construir utopias, transformar a realidade, p. 230-244.

\section{Lutas Sociais e Educação Popular}

científicos da Revista Cadernos do Programa de Pós-Graduação em Direito PPGDir./UFRGS - Qualis B2 (ISSN: 1678-5029 - E-ISSN: 2317-8558).Graduada em Direito pelo Centro de Ciências Jurídicas e Políticas (CCJP) da Universidade Federal do Estado do Rio de Janeiro (UNIRIO).

\section{LEILANE NASCIMENTO DOS REIS SANTOS}

Consultora para o Instituto Raça, Igualdade e Direitos Humanos no Brasil (Race and Equality). Doutoranda em Direito pela Pontifícia Universidade Católica do Rio de Janeiro. Mestra em Direito e Políticas Públicas pela Universidade Federal do Estado do Rio de Janeiro (UNIRIO). Pesquisadora do Grupo de Relações Internacionais e Sul Global (GRISUL/UNIRIO). Membro da Rede Sul-Americana para as Migrações Ambientais (RESAMA). Especializada em Direitos Fundamentais pela Universidade de Coimbra /IBCCRIM, e em Direito Público pela Universidade Veiga de Almeida (UVA). Graduada em Direito pela Universidade do Estado do Rio de Janeiro (UERJ).

\section{LIARA BAMBIRRA}

Graduada em Ciência Política pela Universidade Federal do Estado do Rio de Janeiro (UNIRIO), participou por essa instituição em atividades de ensino, pesquisa e extensão como bolsista e integrou o Núcleo de Assessoria Jurídica e Educação Popular do Centro de Referência em Direitos Humanos. Possui estudos e atuação direcionados a desenvolvimento, gênero, justiça ambiental, movimentos sociais, educação e Sul Global. Atualmente é mestranda no Programa de Pós Graduação de Ciências Sociais em Desenvolvimento, Agricultura e Sociedade (CPDA/UFRRJ) e Coordenadora Político Pedagógica do Pré Vestibular Popular Só Cria. 